\title{
Promoting Learning Practices: Moving Towards Innovation
}

\author{
Chiara Frigerio $^{1}$, Federico Rajola ${ }^{1}$ and Alessia Santuccio ${ }^{2}$ \\ 1 Catholic University, Business and Administration Department, L.go \\ Gemelli 1, 20123 Milan, Italy (chiara.frigerio,federico.rajola)@unicatt.it \\ 2 IULM University, Economics and Marketing Department, via Carlo Bo \\ 1, 20143 Milan, and Catholic University, Business and Administration \\ Department, L.go Gemelli 1, 20123 Milan, Italy \\ alessia.santuccio@unicatt.it
}

\begin{abstract}
As many authors have stated, the importance of organizational learning is fundamental in order to gain competitive advantage and survive in a turbulent environment. Many learning models have been studied in recent years. They have been used to analyze practices or aspects of learning in many industries. This paper aims to develop a particular framework in order to understand the determinants for organizational learning, depending on the firm's general approach towards information and knowledge management. The theoretical framework is derived from Blackler and McDonald's study, which focused on organizational learning approaches, and from Duncan and Weiss's work, which studied attitudes towards knowledge management. This is applied to a particular context characterized by a high level of bureaucracy: the Italian banking industry. In particular, the study is conducted on a sample of 54 banks. The empirical analysis is carried out through questionnaires and interviews. Data is analyzed using statistical analysis. Results are shown and empirical implications are discussed, also in order to explain the reasons for the current situation.
\end{abstract}

\section{Introduction}

Taking Simon [1] as a starting point, who first introduced the concept of organizational learning, this topic has been thoroughly explored over the last few years. Learning practices allow the organization to spread knowledge between members and thus react to external instability $[2,3]$ in order to achieve some kind of success [4]. Organizational learning, in particular, has been defined as the process through which action is improved thanks to a better understanding of context variables [5]. According to Lanzara [6], there can be no organizational learning as long as individual knowledge is not widespread and shared between members. 
Learning is never individual, but always comes from comparisons between members [7]. It is supported by dialogue and communication; collaboration and co-operation; networks of ideas; incentives [8]. This strategy has to be realized at all levels within the organization. This means that even if organizational processes are complex, companies need to maintain learning practices, giving adequate incentives to their members [9]. According to Argyris' [2] definition of learning practices, the concept of organizational learning is also related to that of knowledge. Not many authors, however, have analyzed in any great detail the relationship between the two [10,11]. In fact, the learning loop implies the creation of organizational knowledge, which comes from individuals' shared knowledge. Organizational learning begins from the sharing of individual knowledge, which needs to be spread throughout the organization and easily reached to be subsequently re-used [12].

Analyzing two proposed theoretical models, one concerning organizational learning and the other focusing on the concept of knowledge, this paper formulates a distinct framework. The aim is to explore the following research questions:

1. what are the determinants for organizational learning, depending on the firm's general approach towards information and knowledge management?

2. How can a hierarchical organization move towards innovation through the organizational learning approach?

The paper is organized as follows. Considering the explanation of the theoretical framework, it explains how this is applied to the sample. The results of the empirical study are shown and statistical analysis is presented. The implications are then discussed and some suggestions for future research are offered.

\section{Theoretical Framework}

\subsection{Organizational Learning Perspective}

To study the organizational learning perspective, the paper's approach is based on Blackler and McDonald's study [13], who - in order to investigate the organizational learning cycle - distinguish between four dimensions of learning, which are all present in every organization [13]. This distinction is based on two variables which analyze the complexity of learning practices. Firstly, they consider the (in)stability between organizational groups or networks of members who collaborate, ending up with a distinction between emergent and established ones. Secondly, they focus on the degree of routine which characterizes the relationships between members, distinguishing between emergent and established activities, as showed in figure 1.

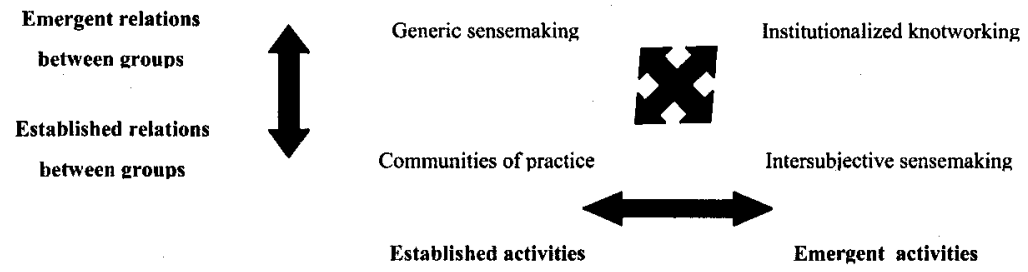

Fig. 1. Blacker and McDonald's dynamics of organizational learning 
According to Cohen and Sproull [14], the distinction between established and emergent activities comes from the level of complexity in conducting them. McCall [15] considers the level of variety and diversity of work required to conduct the activity. Engestrom et al. [16] define an activity as emergent when there is not yet a centre of control for it, when technology or processes or the people involved in them change. An emergent activity always needs new contributions and it is typical of an unpredictable environment. On the other hand, the variable of group stability is classified as established or emergent depending on people's ability to collaborate in a situation of uncertainty [14]. According to Raeithel [17], it depends on the level of familiarity between individuals. Usually in established groups a common aim is created, such as in a community of practice [18].

Adopting Engestrom's view [16], this paper investigates the distinction between emergent or consolidated activities in terms of the presence or absence of a structured learning cycle. When some activity is new, it is not formalized yet; employees manage the activity without following procedures, but by using a nonstructured approach. The activity requires many contributions in order to be improved and also many tools to explain the knowledge about it. So if an organization has more formalized and automated activities, it is considered as characterized by established activities and vice-versa. The paper assumes there is a structured learning cycle when knowledge on activities is firstly formalized and then spread using technological tools. This implies that the structured learning cycle depends on the correlation value of the following two variables:

- level of formalized knowledge in order to conduct the activity;

- degree of automation, which considers the presence and use of technological tools in order to support knowledge sharing and collective learning.

With reference to Cohen and Sproull's [14] and Pautzke's [19] papers, the more the organization allows informal meetings and moments of collaboration, the greater the possibility that knowledge can be shared. If communication between individuals or groups is recurrent and there is a high level of informal coordination (both at top management and staff level), this paper supposes that new relationships and potential new knowledge can emerge within the organization to react to the instability and reach some kind of innovation. The paper's approach considers the relationships as emergent valuating the correlation value of the following three variables:

- frequency of moments dedicated to collaboration;

- level of coordination accomplished through team work (unstructured forms of collaboration), both at business unit and top management level;

- creation of communities of practice and informal teams at all hierarchical levels and the presence of incentives.

\subsection{Knowledge Management Perspective}

As regards the concept of knowledge, this paper refers to Duncan and Weiss's [20] work. The current paper considers their distinctions: reinforcing or innovating through the creation of a new organizational knowledge base. Those aims can be accomplished through organizational or technological tools, as the literature states. As far as the organizational aspects are concerned, Nahapiet and Goshal [21] state 
that the creation of new knowledge is facilitated by the presence of a strong social capital. The importance of a culture of co-operation, collaboration, based on people's autonomy and fair incentives is stated by many authors such as Virkkunen and Kuutti [22]. In addition, Von Krogh et al. [23] analyze the obstacles that lie in the path of knowledge sharing. Also, theories of networks and social interaction explain the importance of promoting physical and virtual relations between individuals in order to create new knowledge $[23,24]$. As well as this, more contributions on this topic come from theories on socialization [25]. The significance of combinative capabilities is offered by [26] or [27] as well. Also the importance of shared experiences and knowledge re-use is explained in Swan et al.'s work [28] and Gray's [29]. Considering the technological perspective, many authors classify technologies which can support a knowledge management approach, new knowledge creation and learning practices. Videoconferences, document management or collaboration tools are mentioned as useful tools $[30,31]$. With reference to evidence in literature, the paper distinguishes between reinforcing and innovating the knowledge base by statistically analyzing the following:

- technological and organizational tools of KM;

- culture and incentives.

Considering these two perspectives on, respectively, organizational learning and knowledge management, the paper's theoretical framework is the following:

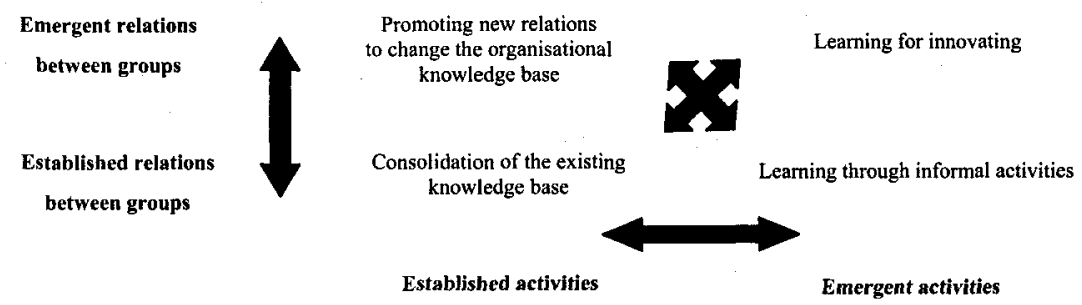

Fig. 2. Organizational learning and knowledge: an integrative approach

The aim of the paper is to demonstrate the differences in organizational practices and technological tools which explain the differences in knowledge sharing and learning between different clusters.

\section{Research Methodology}

The study is conducted on the banking industry. The reason for choosing this particular industry is the rapid changes that banks are experiencing, which need to be supported by learning practices, in order to react to the uncertainty of change (normative changes, the need to address customer satisfaction and follow market trends, international competition etc.). Moreover, to answer the second research question, questionnaires are completed and interviews conducted. Of 100 questionnaires distributed, $54 \%$ were completed and returned to be analyzed. 
Considering the dimension variable, based both on the amount of intermediate funds - according to Bank of Italy directives - and on the number of employees, the sample is composed as follows:

- $38.9 \%$ (21 units) small banks;

- $33.3 \%$ (18 units) medium banks;

- $27.8 \%$ (15 units) large banks.

Quantitative data is collected thanks to structured questionnaires, filled in by KM managers (where possible), organizational and/or IT managers. Questionnaires are divided into two parts. The first one regards the bank's description; the second part concerns more specifically the current situation of learning practices, which are studied both from the organizational and technological point of view (practices and tools which support learning processes). People who were interviewed through questionnaires could answer the statements by choosing from a range between 1 and 7 (the answer is based on the Likert scale). The sample is classified using a cluster method. For each cluster a certain number of correlations are included, in order to understand the distinctiveness of each group. 6 interviews were also carried out (a couple for each size). They allow us to collect qualitative data in order to understand better the reasons for implementing some choices instead of others and extract tacit information and knowledge on the firm's processes of learning.

Data collection starts in November 2003 and finishes in July 2004.

\section{Findings and Discussion}

\subsection{Clustering the Sample's Relations and Activities}

The initial classification of the sample, based on Blackler and McDonald's study, is conducted by investigating those variables proposed in paragraph 2.1 through cluster analysis. In particular, to find out whether a bank has more established than emergent activities, the degree of formalization and automation is considered for each activity (payments, risk management and auditing, marketing etc.) and their means are calculated for each bank. The institution is characterized for established activities if the means of formalization and automation are, at the same time, greater than 4 (on a 1 to 7 scale). The same statistical analysis is conducted as regards the relationship variable, evaluating the average of the three variables proposed in the theoretical framework: the moments of collaboration, informal coordination and presence of incentives to the creation of informal teams.

In figure 3 cluster analysis output is presented, showing the number of banks which belong to each cluster. The results show that the majority of the banks have more established than emergent relationships and activities. Indeed, the banking industry has always been known for its high level of control, rigid procedures, formalized processes and hierarchical structure. This is due to the kind of activity it carries out: banks are risk adverse. Consequently, they strictly follow the rules. Over the last years there have been very few examples of investments made towards the creation of informal teams or communities in order to promote creativity, learning and knowledge exchange and when they can be found they only concern specific projects, such as Basel 2. 
Table 1. Cluster analysis results

\begin{tabular}{|l|c|c|c|}
\hline \multirow{2}{*}{ Relationship } & Emergent & 12 (cluster 4) & 6 (cluster 2) \\
\cline { 2 - 4 } & Established & 18 (cluster 3) & 18 (cluster 1) \\
\hline \multirow{2}{*}{} & Established & Emergent \\
\cline { 2 - 3 } & \multicolumn{2}{|c|}{ Activity } \\
\hline
\end{tabular}

At this point, a list of variables is considered through correlation analysis and the statistical significance is illustrated for each one of them (Table 2). The aim is to find out if they are relevant in order to explain differences in the way the four clusters go through the learning process, considering the organization's general approach towards information and knowledge management.

Table 2. Variable statistical significance

\begin{tabular}{|c|c|c|}
\hline Variable & $p$ & Significance \\
\hline Dimensional class & $>0.05$ & Low \\
\hline Current situation of knowledge management systems & $<0.01$ & Medium \\
\hline Hierarchical level of knowledge management systems implementation & $<0.01$ & Medium \\
\hline Employment and dismissal rates & $>0.05$ & No \\
\hline Job rotation & $>0.05$ & No \\
\hline Responsible or sponsor of learning projects & $<0.01$ & Medium \\
\hline Use of technological tools & $<0.001$ & High \\
\hline $\begin{array}{c}\text { Use of virtual spaces to support long distance learning and knowledge } \\
\text { sharing }\end{array}$ & $<0.001$ & High \\
\hline $\begin{array}{c}\text { Incentives to knowledge sharing and learning practices } \\
\text { Kind of decisions supported by learning practices and knowledge } \\
\text { management systems }\end{array}$ & $<0.01$ & Medium \\
\hline
\end{tabular}

The dimension variable does not explain the variability between clusters. Anyway, while cluster 1 is mainly composed of large banks, clusters 2, 3 and 4 are made up of, respectively, small-medium, small and medium-sized banks. Generally, all these clusters consider learning practices important in order to maintain a competitive advantage. There is a divergence, however, in the way they promote them and some variables do not explain the clusters' differences in learning practices, such as employment and dismissal rates. What makes the difference between clusters is the dissimilarity in tools that emergent and established activities use to promote learning. While banks with prevalent emergent activities are based on both paper and electronic communication, established ones communicate mainly by electronic means. This evidence can be explained in terms of knowledge formalization and the use of it to promote learning practices at a distance too. Knowledge of consolidated activity is made explicit and formalized, while regarding emergent activities - new concepts are continually in evolution. These are not strongly formalized and distributed through electronic tools yet. The low importance placed on electronic tools is explained also by the significance of knowledge management. In cluster 2 great importance is given to opportunity for collaboration, while investments in technology are not high. This can be explained looking at the main cluster's characteristics, which is characterized by emergent 
relationships between groups and emergent activities. The main focus is on the people variable, in order to promote innovation. Investments cannot be high because of the predominantly small size of the banks which are involved. In cluster 1, processes and technology are both considered equally important. These mainly large banks formalize knowledge and distribute it using technology. Investments in IT are consistent because of the size - these banks can afford them and also permit a higher level of communication and reduce bureaucracy-connected risks. This also regards cluster 4 , characterized by banks which are not small. Finally, banks in cluster 3 give importance to people working together to promote organizational learning, but also to processes, while IT investments are not high because of the small size. Also while clusters characterized by established activities give importance to learning practices at business unit and top management level, cluster 2 focuses mainly on business unit level. Cluster 4 is the only one which implements a learning culture also at branch level, even if these banks place moderate importance on learning as a tool of innovation. This cluster differs also because of the kind of decisions the learning cycle supports. While in clusters 1,3 and 4 the learning process supports daily and operational decisions, in cluster 2 it also supports the strategic ones. As concerns the presence of a learning project sponsor, the difference between clusters mainly depends on the way banks interpret the learning process and what they focus on. Only in cluster 3 this responsibility is given to the human resources managers, since these banks interpret the learning approach as the management of people. Generally, in all clusters the persons responsible and sponsor for learning projects are the CIO (especially in cluster 4), CEO or heads of departments. The main reasons for spreading organizational learning practices between members differ depending on the aim of learning. In clusters with established activities, the aims of a learning approach are the efficiency and effectiveness of process management, better formalized knowledge, competence sharing and a better process of communication. On the other hand, clusters characterized by emergent activities implement learning practices firstly, in order to introduce some innovation, and secondly to improve communication between members or groups and efficiency in process management. Cluster 2 shows an interest in reducing the time taken to reach the market, supported by flexible organizational learning.

In order to support an effective approach toward learning, management commitment seems to be the most common incentive between clusters. Banks, generally, do not adopt strategies such as bonuses, benefits, or career improvements. What is evident is a lack in promoting formal learning. Porter and Lawler's [32] theory of motivation suggests the mixing of different incentives, to promote learning in a better way by aligning the individual and organizational interests. As regards the use of technological tools, clusters with emergent relationships are based on collaboration tools. Generally, all clusters present repositories on the web (usually intranet and portals) to spread knowledge. E-mails and videoconferences are the most widespread mechanisms of learning, while it is not the same as regards brainstorming and forums.

The empirical study also shows whether there are obstacles in the learning practices. In cluster 1 , there is the perception that learning is a waste of time and useless. In many cases personal knowledge is considered as a source of power [33], useful mainly to build up one's personal career. In cluster 2, which has a more 
innovative approach towards learning, the main obstacle is the kind of relationships that exists between members. Even if these banks are characterized by emergent relationships, the ones which already exist are not flexible enough. This depends on the way of conducting banking activities, which do not require a highly flexible relationship between members. Cluster 3 complains that there is poor competence in the use of technological tools, but also considers learning - as cluster 1 does - a waste of time. Cluster 4 criticizes lack of skills to support the learning cycle.

\subsection{The Main Approaches towards Organizational Learning}

Considering the determinants of learning proposed for each cluster, this paper takes 4 main approaches towards learning inside the banking industry, which differ from each other in the way activities and relations are managed, but also for the current situation of knowledge management tools to support it. The differences between approaches are presented in table 3 and discussed.

Cluster 1 adopts what here is called informal learning. This cluster is characterized by mainly large banks. The most important aim seems to be the management of bureaucracy in order to drive the organization towards flexibility. The main obstacle is the evidence that people do not want to share their knowledge. There is also evidence that people are poorly managed: few incentives are present and the culture is still too bureaucratic; this may be because of the large size. The focus is on processes and large investments are made in technology. On the other hand, cluster 4 promotes a learning approach based on the creation of new relationships. Activities are consolidated and well formalized, which means that knowledge is made explicit. The focus is on competence sharing and communication through technological tools, such as collaboration tools. A big obstacle, however, is present, which is the lack of support in order to promote learning. Cluster 3 is characterized by a focus on coordination, which seems to be achieved perhaps because of the fact that the banks are not large. The main limitation is the particular attention this cluster pays to established relationships, while an innovative approach should also promote new ones. Because of the poor investments made in IT and the lack of IT competence, the learning process is found mainly in skill sharing and communication. Virtual learning techniques are not so widespread. Finally cluster 2 is considered the most innovative one as regards learning practices; it still involves a minority of the analyzed sample. The main aim consists of reducing the time it takes to reach the market, which can be achieved only if activities are carried out in a flexible way. New relations and activities are always created or modified to allow for the alignment with changes. To do so, opportunities for collaboration are created to promote the sharing of ideas between members and groups, also using technological tools such as collaboration tools. But obstacles are also present. Banks have to focus on the kind of relationships that exist between members, which in the banking industry have always been characterized by rigidity. A change in this is underway. The commitment appears to be intense. It promotes a learning culture which is essential in order to have innovation. 
Table 3. Main differences between clusters

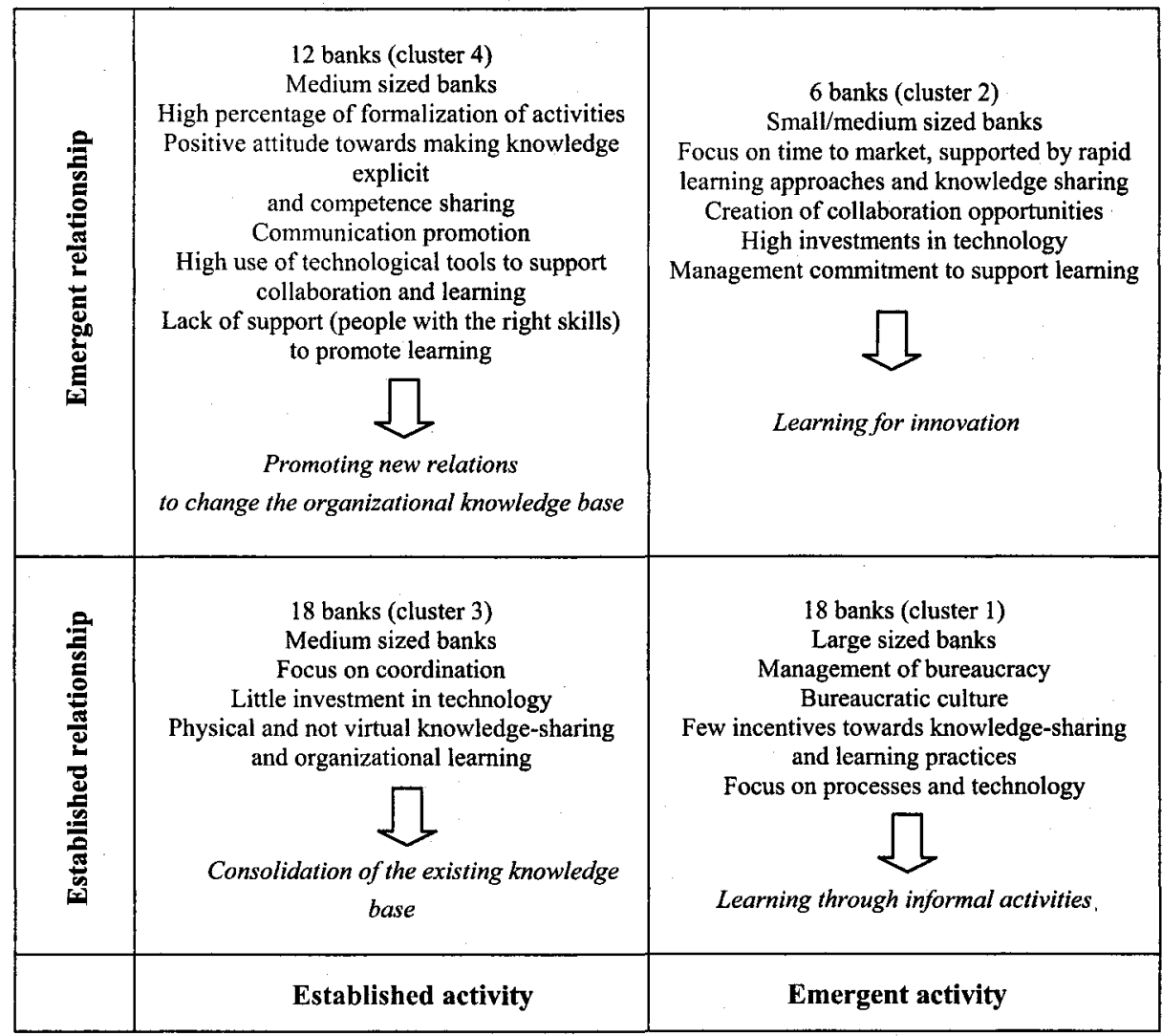

If the number of banks in each cluster is considered, the evidence is that there are still too many organizations characterized by a bureaucratic approach in the way they manage business. In order to promote more flexibility in learning, and so move toward cluster 2, banks need to consider all the other clusters' approaches. Innovative learning needs to consolidate the existent knowledge to create a new one (cluster 3). But this is only possible by promoting new relationships between employees (cluster 4) and also focusing on informality of action, to reduce the bureaucracy-connected risks (cluster 1). The banking industry is expected to become more flexible, to favor the exchange of knowledge between members and groups, and to increment learning practices. This is possible by acting on culture, trying to reduce the "not invented here" syndrome, which represents a big barrier to the diffusion of collective learning practices. As Shein [34] says, emergent learning strongly depends on the historical context, on the organization's culture and beliefs. 


\section{Conclusion and Future Research}

As concerns the determinants for organizational learning, the paper has shown those variables which differ between banks, depending on the specific attitude toward information and knowledge management they develop. In particular, the main differences refer to the following variables: the presence of technological tools which support knowledge management, the culture, incentives used toward knowledge sharing and individual learning, informal cooperation, opportunities for collaboration, the presence of virtual areas for long distance learning and the kind of hierarchical decisions the organizational learning approach supports. As regards the second question under research, the hierarchical organization's move towards innovation through the learning attitude consists of a couple of steps. The first one is the need to promote new relationships between members or groups in order to change the organizational knowledge base. In this way a flexible approach is adopted, which allows the organization to give importance to new ideas, to anticipate external changes and adapt to environmental instability. On the other hand is the need to promote new activities. This paper underlines the importance of an initial informality in the way new activities are approached. In fact, a reduction in the formalization of activities allows the organization to reduce bureaucracy and acquire some degree of flexibility, which is the starting point for innovation purposes.

Some of the limitations in the research must be mentioned. The paper's theoretical framework has been useful in order to classify the sample of banks using the cluster analysis. The main limitation refers to the variables choice. Certain indicators have been used, while others have been rejected because of the impossibility to analyze all of them at the same time.

Finally, this paper proposes a particular theoretical framework in order to connect knowledge management and learning methodologies, but it focuses on a particular industry, which is characterized by its high level of rigidity. This is the reason for suggesting a further analysis and comparison of these results with those conducted on learning practices in other industries. The expectation would be to discover, for example, a different way of learning which is widespread, for example, in hi-tech industries. In fact, their reason for being is based on knowledge sharing practices and learning practices. It would be interesting to analyze whether the banking industry can reach the degree of flexibility that characterizes other industries.

\section{References}

1. H. A. Simon, Administrative behaviour (The Free Press, New York, 1976).

2. C. Argyris, Action science and organizational learning, Journal of Managerial Psychology 10(6), 20-26 (1995).

3. E. H. Schein, How can organizations learn faster? The challenge of entering the green room, Sloan Management Review 34, 85-92 (1993). 
4. P. M. Senge, The fifth discipline: the art and practice of the learning organization (Currency Doubleday, New York, 1990).

5. C. M. Fiol, M. A. Lyles, Organizational learning, Academy of Management Review 10(4), 803-813 (1985).

6. G. Lanzara, Le mappe cognitive degli attori organizzativi, Rivista Trimestrale di Scienza dell'Amministrazione 4, (1990).

7. M. Easterby-Smith, M. Crossan, D. Nicolini, Organizational learning: debates past, present and future, Journal of Management Studies 6(37), 783-796 (2000).

8. K.E Watkins, V.J. Marsick, Sculpting the learning organization: lessons in the art and science of systemic change (Jossey-Bass, San Francisco, 1993).

9. M. Glynn, F. Milliken, T. Lant, in: Advances in managerial cognition and organizational information processing, edited by C. Stubbart et al. (CT: JAI Press, Greenwich, 1994), pp. 48-83.

10. C. Argyris, D. Shon, Organizational learning: a theory of action perspective (Reading, MA: Addison-Wesley, 1978).

11. R. Lipshitz, M. Popper, S. Oz, Building learning organizations: the design and implementation of organizational learning mechanisms, Journal of Applied Behavioral Science 32, 292-305 (1996).

12. I. Nonaka, H. Tacheuki, The knowledge creating company (Oxford University Press, New York, 1995).

13. F. Blackler, S. McDonald, Power, mastery and organizational learning, Journal of Management Studies 37(6), 833-851 (2000).

14. M. Cohen, L. Sproull, Organizational learning (Sage, London, 1996).

15. M. W. Jr. McCall, in: Perspectives on behaviour in organizations, edited by J. R. Heckman et al. (McGraw Hill, New York, 1977), pp. 375-386.

16. Y. Engestrom, R. Engestrom, T. Vahaaho, in: Activity theory and social practice: cultural-historical approaches, edited by S. Chaiklin et al. (Aarhus University Press, Aarhus, 1999), pp. 342-367.

17. A. Raeithel, in: Cognition and communication at work, edited by Y. Engestrom at al. (Cambridge University Press, Cambridge, 1996), pp. 319-339.

18. E. Wenger, W. Snyder, Communities of practice: the organizational frontier, Harvard Business Review 78(1), 139-145 (2000).

19. G. Pautzke, Die evolution der organisatorischen Wissensbasis (Herrsching: B. Kirsch, Munchen, 1989).

20. R. Duncan, A. Weiss in: Research in organizational behaviour, edited by L. Cummings and B. Staw (JAI Press, Greenwich, 1979), pp. 75-123.

21. J. Nahapiet, S. Goshal, Social capital, intellectual capital and the organizational advantage, Academy of Management Review 23, 242-266 (1998).

22. J. Virkkunen, K. Kuutti, Understanding organizational learning by focusing on activity systems, Accounting Management and Information Technologies 10, 291319 (2000).

23. G. Von Krogh, K. Ichijo and I. Nonaka, Enabling Knowledge Creation (Oxford University Press, Oxford, 2001).

24. B. Latour, S. Woolgar, Laboratory Life: The Construction of Scientific Facts (Thousand Oaks: CA: SAGE, 1979).

25. I. Nonaka, A dynamic theory of organizational knowledge creation, Organization Science 5(1), 14-37 (1994).

26. B. Kogut, U. Zander, Knowledge of the firm, combinative capabilities and the replication of technology, Organizational Science 3, 383-397 (1992). 
27. R. M. Grant, Prospering in dynamically competitive environment: organizational capabilities as knowledge integration, Organization Science 7(4), 375-387 (1996).

28. J. Swan, H. Scarbrough, M. Robertson, The construction of communities of practice in the management of innovation, Management Learning 33, 477-496 (2003).

29. P. H. Gray, The effects of knowledge management systems on emergent teams: towards a research model, Journal of Strategic Information Systems 9, 175-191 (2000).

30. U. Borghoff, R. Pareschi, Information Technology for knowledge management (Springer-Verlag, New York, 1998).

31. R. L. Ruggles, Knowledge management tools, (Butterworth-Heiniemann, Boston, 1997).

32. L. Porter, E. Lawler, Managerial attitude and performance (Homewood, Illinois, 1968).

33. W. C. Kim, R. Mauborgne, Fair process: managing in the knowledge economy, Harvard Business Review 7/8, 65-75 (1997).

34. E. Shein, Organizational culture and leadership (Jossey-Bass, San Francisco, 1992). 